\title{
The Role of Ethnic-Based Social Capital in Establishing the Spatial Consensus Among Urban Growth Coalitions
}

\author{
Mohammad Hossein Sharifzadegan \\ University of Shahid Beheshti, Tehran, Iran. \\ Pouya Joudi Gol lar \\ University of Shahid Beheshti, Tehran, Iran. \\ Behzad MalekpourAsI \\ University of Shahid Beheshti, Tehran, Iran
}

\begin{abstract}
Local power structure in the framework of urban growth coalition theory includes a set of property owners and place entrepreneurs who pursue their goal in establishing and maintaining consensus, providing the right conditions for outside investment and maximizing the "rents" by trapping human activities in place. Social capital, as part of the social structure, is the collective capacity of social groups for cooperation and common function to achieve public good. By translating public good to urban growth in physical context, urban coalition strives to construct a city environment in which the citizens come to the agreements and establish social relationships to maximize the profits from urban growth. Therefore, one can ascertain social capital as an instrument for dominance of urban growth coalition on urban politics. The overall aim of this article is to explore ethnic-based social capital, its crucial role on establishing consensus and facilitating the development of relationships between members of urban growth coalition, and seeks to analyze mechanisms that generate ethnic-based social capital so that urban coalition uses all networked positions and social linkage to achieve its goals.
\end{abstract}

Keywords: social capital, urban, growth coalition, place entrepreneur.

\section{Introduction}

In recent years the role of social capital - defined as the institutions and networks of relationships between people, and the associated norms and values - has risen to considerable prominence in programs of poverty alleviation and development. Although development practitioners have long suspected that social capital affects the efficiency and quality of most development processes (Grootaert \& van Bastelaer, 2002). There are two broad intellectual streams in description and explanation of social action. One, characteristic of the work of most sociologists, sees the actors as socialized and action as governed by social norms, rules, and obligations. The principal of virtues of this intellectual stream lie in its ability to describe action in social context and to explain the way action is shaped, constrained and redirected by the social context. The other intellectual stream, characteristic of the work of the most economists, sees as the actor as having goals independently arrived at, as acting independently, and as wholly self-interested (Dukić, 2012). In this paper both intellectual approach has been used to explain and description of urban growth coalition.

\section{Social capital as concept}

Social capital is a controversial, although still surprisingly popular, concept. In its more recent manifestations, it has a motley past, coming through and moving between differing academic disciplines, principally political science, economics, economic development, education and sociology. Whilst this capacity to be recognized and used in a range of disciplines has been seen as a positive and integrative characteristic by some, others have seen it as the source of confusion and definitional 
problems that are regarded as besetting the concept. Anne Kovalainen sees the inherent appeal of social capital as that it is at one and the same time an economic, a political and a sociological concept, giving it inter disciplinary prominence and potential (Kovalainen, 2004); Michael Woolcock (2001) sees it as freed in this regard from the constraints of particular disciplinary traditions. But Ben Fine (2001), Virginia Morrow (1999) and Alejandro Portes (1998) point to the fuzziness and chaos that the concept trails in its wake, working previously distinct perspectives together to suit its own hybrid construction (Holland, 2009).

As Fukuyama (1999) argues, while social capital has been given a number of definitions, many of these refer to manifestations of social capital rather than social capital itself. For the purposes of this article I want to concentrate on the work of Putnam in operationalizing the concept of social capital. According to Putnam (2000: 19) 'whereas physical capital refers to physical objects and human capital refers to properties of individuals, social capital refers to connections among individuals - social networks and the norms of reciprocity and trustworthiness that arise from them'. Putnam suggests that communities with a 'good' stock of social capital are more likely to benefit from lower crime figures, better health, higher educational achievement and better economic growth. His perspective concurs with the political science view of social capital as concerned with civic engagement and trust at the level of communities and regions and how these foster the development of civic trust in political institutions (Leonard, 2004).

As Woolcock points out (2001) there is an emerging consensus regarding the definition of social capital - a consensus borne out of considerable debate and empirical investigation. We follow his lead with only slight modification by defining social capital as the social networks and their associated norms that may facilitate various types of collective action. This definition avoids the confusion that has been introduced by the inclusion of specific types of outcomes into the definition of social capital itself (Reimer, Lyons, Ferguson, \& Polanco, 2008).

\section{2-1- Social capital in networks and reputation}

The two approaches to social capital will be considered jointly, due to their strong interrelationship: the first approach is social capital in networks, and the second is social capital as reputation. Network theory is vast and its relation to social capital disputed. However, many social capital authors regard network claims to be too insular and overblown. Putnam (2000: 172), for instance, argues that network theory is limited and quotes the Palo Alto Research Center in relation to the ultimate network, the Internet, saying 'that information itself needs a social context to be meaningful'.

It is not surprising that there are a number of ethical concerns over the network approach to social capital, given the universal claims made for this approach. Thus, it has been argued that the network approach to social capital is overly mechanical and arguably strips individuals and groups of their emotional and instinctive need for social interaction, within a syntax more suited to computer circuitry. Moreover, Fukuyama (2000) has argued that 'Networks, understood as informal ethical relationships, are therefore associated with phenomena like nepotism, favouritism, intolerance, in-breeding, and non-transparent, personalistic arrangements'. Such perspectives are entirely in conflict with Kant's moral imperative for universalizability so that all individuals must be treated in the same way according to rational principles, rather than relationship based (i.e. he claimed we should not favour a relative over a stranger) (Ayios, Jeurissen, Manning, \& J. Spence, 2014).

The networks view of social capital, which derives many of its theoretical positions from social network analysis (SNA), argues that conceptualizing social capital as an asset held at the individual level allows scholars to differentiate its causes from its outcomes. Valued resources are embedded in social structures characterized by distributional and rank differences. The higher the rank, the greater the concentration of valued resources, in other words, the better the position of origin in a social network, the more likely the actor will access and use social capital (Lin, 2001).

Bourdieu, one of the most influential theoreticians among networks specialists, argued that a person's social capital could be asserted by aggregating: 1) the size of his or her network and 2) the volume of social, cultural, and economic capital of the network members (1986 in Zhao 2002). From his perspective, embedded resources such as information and the influence of its members are social capital. Lin (2001) has further refined this conceptual framework by seeing social capital as assets located in networks which can be measured through two main categories: 1) as embedded resources and 2) as network locations. The first one refers to the power, wealth, and influence available in a network and the resources that each contact in the network can provide. The second is more concerned with the structure of the network and how certain characteristics of a network, such as actors acting as bridges facilitate or impede returns to other actors. Beyond the 
explanatory technicalities of formal network analysis, the point is that social capital is a resource that is differentially available to individuals depending on where they stand in the structure of relations of the group. Class, race, ethnicity, religion and gender, to name some, are categories that position social actors in the structure of social relations. In other words, whatever forms of stratification and inequality are at play in the constitution of social life in a community, they will be reflected in the processes of participation in its formal associations (Reimer, Lyons, Ferguson, \& Polanco, 2008).

The issue of trust is developed further in our third related theme of social capital as a reputation theory, which analyses levels of trust and credibility, and in the economic context conceptualizes reputation as a capital asset to be promoted and protected. For example, from an economic understanding of social capital, Dasgupta (2005) argues that the role of mutual enforcement in repeated interactions is to create 'a creditable threat by members of a community that stiff sanctions would be imposed on anyone who broke an agreement could deter anyone from breaking it'. The threat's credibility would be grounded in 'rules of behaviour' or social norms.

Putnam sought to distinguish between bonding and bridging social capital, arguing that the former is likely to have illiberal effects because it seeks to build networks of the already like-minded to the exclusion of others (Putnam, 2000). Bridging social capital, he argues, which builds connections across groups and is inclusive in nature, offers the potential to solve some of society's most intractable problems (Putnam, 2000).

\section{2-2- Bonding and Bridging Social Capital}

In the critique of Putnam's work, Portes and Landolt (1996) suggest that in some cases, social capital can become a constraint to individuals' actions and choices. This is because social capital may stem from excluding others from access to resources. In his work on regional differences in social capital in Italy Putnam (1993) considered social capital as a positive resource and the possibility that the concept may have only partial benefits was not fully acknowledged.

However, in his later writings, Putnam (2000) addresses this criticism by making a distinction between bonding (exclusive) and bridging (inclusive) social capital. Bonding social capital occurs among homogeneous populations. (Leonard, 2004)

It is often parochial and only benefits those with internal access. While it can act as an effective resource for particular groups such as ethnic minority groups who create niche economies, its benefits are limited. The very factors that promote its development such as tight bonds of trust and solidarity may ultimately prevent its entrepreneurial members from reaching their full potential. They may be held back by family and community demands and will only become successful if they are able to forge ties with others in the wider society. In other words developing bridging social capital. Quoting Briggs, Putnam (2000) argues that bonding social capital is good for 'getting by' but bridging social capital is essential for 'getting ahead'. It is this notion of bridging social capital that has captured the imagination of policy makers.

Embedded in Putnam's notion of social capital are concepts such as trust, community, networks and reciprocity which have a long history. Indeed these concepts form part of the building blocks of both sociology and anthropology.

The incorporation of these older concepts into the theorization of social capital has led Portes to question the newness of social capital as a sociological concept. According to Portes (1998: 2) 'Despite its current popularity, the term does not embody any idea new to sociologists. That the involvement and participation in groups can have positive consequences for the individual and community is a staple notion that dates back to the work of Durkheim and Marx'. To the workings of these concepts are issues to do with inclusion and exclusion. Putnam's distinction between bonding and bridging social capital does not go far enough in acknowledging the inherently unequal features of both bonding and bridging social capital.

There are two main problems with Putnam's treatment of bonding and bridging social capital. Firstly, in Putnam's analysis, bonding social capital is unequal because it excludes those outside the community residing in other communities but at the local community level it is inclusive. This conclusion is debatable. Secondly, Putnam implies that making the transition from bonding to bridging social capital benefits the community as a whole rather than perhaps some individuals in the community. By drawing on a case study from Northern Ireland, the article demonstrates that this analysis is too simplistic (Leonard, 2004). 


\section{3- Applying ethics to social capital: exploring the dark side}

Most approaches to social capital stress the positive externalities of social connections and informal relationships which are theorized to result in trust, shared norms, solidarity and civic mindedness. As Field (2003) observes: 'there shines out a warm glow. Social capital's "dark side", by contrast, remains largely unknown terrain'. Portes (1998) summarises problematic aspects of social capital as being 'at least' the exclusion of others, excessive claims on members of the group, restrictions on individual freedoms, group closure and the downward levelling of norms based on group solidarity. Other related outcomes include distrust and lack of cooperation, thereby impeding - rather than enhancing - economic progress.

Putnam also recognizes the potential limitations of the emphasis on shared norms, languages and networks, when he cautions over the 'Dark Side of Social Capital' (Putnam, 2000: 350-363) and concedes that there is a 'classic liberal objection to community ties: community restricts freedom and encourages intolerance' (Putnam 2000: 351). For example, in the 1950s, a 'surfeit of social capital seemed to impose conformity and social division' (Putnam, 2000: 352). This dark side is given voice in a collection of criticisms that interpret Putnam's social capital as class based, and elitist for providing a bulwark in favour of the prevailing economic policies.

This can apply as much in the perpetuation of elites or key groups in the workplace as in wider society, and is reminiscent of Bourdieu's (1986) conceptualisation of social capital as relating to 'privileged individuals [who] maintain their position by using their connections with other privileged people'. Based on this, it is easy to spot the potential moral deficiencies of social capital in simple statements such as those of Lin, defining social capital as 'embedded resources in the networks accessed and used to attain status' (Lin, 2001). Social capital is premised on 'investment in social relations with expected returns in the market place' (Lin 2001), or put simply: 'It's not just what you know but who you know' (Lin, 2001). It is our task in the current paper to add some precision to these broad indications of ethical problems associated with social capital.

To sum up the arguments regarding social capital's 'dark side', it is a resource that can be subject to high levels of selectivity and manipulation by actors using it and those subject to it, and this can lead to great inequalities and perverse outcomes in the attainment of optimum 'economic outcomes'. Such concerns lead Adler and Kwon to conclude that: 'social capital research would benefit from a more systematic assessment of risks as well as benefits . . . One actor's social capital advantage is often another actor's disadvantage, and research on the differential access to social capital is therefore a high priority (Lin, 1999; Adler \& Kwon 2002: 35). This is the basis for the current paper, which seeks to deepen our understanding of social capital's dark side from an ethics perspective.

\section{3-1- Four aspects of social capital}

Based on Remier et al (2008), we differentiate four very general types of normative structures that guide behavior in social relations: market, bureaucratic, associative, and communal. These four types of normative structures represent four relatively comprehensive ways in which people organize their interactions to accomplish tasks, legitimize their actions, distribute resources, and structure their institutions. Each of these has its own general set of associated norms that condition the co-ordination of social behaviour.4 since social capital is reflected in and derived from these relations, it is conditioned by the same norms and sanctions as those relations.

Market relations are those in which the classical norms of 'open' and 'free' exchange of goods and services occur between relatively free actors (Reimer, 2008). Market-based social capital is created, built, and maintained through fair trade of goods or services, sharing of information about markets and prices, and the demonstration of appropriate negotiation skills in the process.

Bureaucratic relations are the 'rational-legal' relationships originally explored by Weber (1978). They are impersonal and formal, with the distribution of resources based on generally-applied principles and status positions rather than productivity. The charters and by-laws of government and corporate organizations are key points of reference for identifying the allocation of rights and entitlements. Bureaucratic-based social capital is built through the formulation of these charters along with the maintenance of legitimacy, either formally or informally.

Associative relations are based on shared interests. Clubs, social action groups, internet chat rooms, spectator events, hobby groups, and food banks are examples where these relations predominate. Associative-based social capital emerges when interests coincide and where there is a common contribution to the goals on the part of members. It is built through 
the successful accomplishment of those goals, the achievement of objectives en route to them, or the reinforcement of promises to achieve those goals. (Putnam, 2001).

Communal relations are based on a strong sense of shared identity. Membership and collective action within communal relations are often dependent on ascribed characteristics of birth, ethnicity, or location but they may also emerge as a result of shared life experiences or intense socialization. Family, friendship, cult, and gang activities are common examples of such relations.

The rights and obligations of members are strongly associated with this identity, and are largely developed and maintained through customs (Hamilton and Biggart, 1992).

All four usually occur concurrently in a given situation, although only one or two may be dominant. This may be seen in an office setting where workers' behavior is primarily guided by market and bureaucratic norms, even as they may be supported by the communal and associative ones inherent in informal social relations. Still, this is not always the case, since one relation may inhibit another. Volunteer group participants in our field sites, for example, often complain that the inflexible demands of their bureaucratic based funding agencies undermine their original objectives, or divert them to a more limited set of goals. We develop and enforce regulations in our municipal decision-making to guard against communalbased patronage allocation of contracts and resources (Remier et al, 2008).

\section{4- The Political Economy of Urban Power Structures}

A local power structure is at its core an aggregate of land-based interests that profit from increasingly intensive use of land. It is a set of property owners who see their futures as linked together because of a common desire to increase the value of their individual parcels. Wishing to avoid any land uses on adjacent parcels that might decrease the value of their properties, they come to believe that working together is to the benefit of each and every one of them. Starting from the level of individual ownership of pieces of land, a "growth coalition" arises that develops a "we" feeling among its members even if they differ on other kinds of political and social issues.

In economic terms, the "place entrepreneurs" at the center of the growth coalitions are trying to maximize "rents" from land and buildings, which is a little different than the goal of the corporate community -- maximizing profits from the sale of goods and services ${ }^{1}$ :

Unlike the capitalist, the place entrepreneur's goal is not profit from production, but rent from trapping human activity in place. Besides sale prices and regular payments made by tenants to landlords, we take rent to include, more broadly, outlays made to realtors, mortgage lenders, title companies, and so forth. The people who are involved in generating rent are the investors in land and buildings and the professionals who serve them. We think of them as a special class among the privileged, analogous to the classic "rentiers" of a former age in a modern urban form. Not merely a residue of a disappearing social group, rentiers persist as a dynamic social force.

The most important activity of a local growth coalition is to provide the right conditions for outside investment. This preparation involves far more than providing level and plentiful acreage with a stream running through it. It also involves all those factors that make up what is called a "good business climate," such as low business taxes, a good infrastructure of municipal services, vigorous law enforcement, an eager and tame labor force, and a minimum of business regulations.

The growth-coalition hypothesis leads to certain expectations about the relationship between power structures and local government. Rather obviously, the primary role of government is to promote growth according to this view. It is not the only function, but it is the central one, and the one most often ignored by those who write about city government. Local government promotes growth in several ways, the most visible of which are the construction of the necessary streets, sewers, and other public improvements and the provision of the proper municipal services. But zoning, building standards, and many other government regulations also matter greatly in keeping property valuable, as home builders also realized very early in the 20th century. While all of this is going on, the city departments of planning and public works, among several, become allies of the growth coalition with the hope that their departments will grow and prosper (Mollenkopf, 2000).

\footnotetext{
${ }^{1}$ As sociologists Jonathan Logan and Harvey Molotch explain. Logan \& Molotch, 1987.
} 
The critical players in such coalitions are said to be those elements within capital which are most place bound, that is to say rentiers (property owners) who rely on an intensified use of land or buildings in a particular area for enhanced profits. They are joined by those who benefit from the intensification process itself-in the terms used here, those with an interest in treatment and servicing — and also by interests who benefit from the increased demand for their products brought about by economic (income and/or population) growth (Harding, 1991).

\section{4-1- Peasant Coalitions}

Wolf, saw two main types of coalitions that define peasant social relations: those that bring people together around a single interest, and those in which its members share multiple interests (1966: 81). The first he called singlestranded, the second one, manystranded. In single stranded coalitions, two or more persons join forces with the purpose of advancing a specific goal. An example is rural associations such as funeral groups, irrigation and producers associations. Members of this type of coalition are usually bound by a particular interest, which does not necessarily demand that its participants be involved with one another beyond this cause. A manystranded coalition, on the other hand: "is built upon through the interweaving of many ties, all of which imply one another" (1966: 81). Economic transactions may be influenced by kinship relations, which in turn may require specific obligations and rights; furthermore, these might limit the range of options in other spheres of life. Each type of relation is like a strand; together they provide great security to people at different levels. On the other hand, this interlocking of strands is the source of its own weakness as they tie people together into inflexible relations that are difficult to disentangle. An idea similar to the negative side of social capital, where closed and bounded groups contravene the benefits of building a network of relations as they are unable to build bridges.

\section{4-2- The Role of Ethnic-Based Social Capital in Urban Growth Coalitions}

Achieving urban development through increased social capital is one of the most important sociological objectives for nations in the 21st Century (Bartelsman 2000). Because of the close relationship between urban growth and community prosperity, economists seek recognition of policies for realizing growth. Urban productivity, together with other core urban development concepts such as competiveness, are usually focused on the sub-national urban economic development process of the home country (Castellani 2011). However, recent experience has documented an increase in the internationalization of urban productivity and related activities (Fukuchi 2000). This was initially and mainly motivated by the need to better exploit existing home-based or urban growth coalition, while more recently the need to source complementary assets and competences abroad has become an important motive.

The definitions and meanings of urban growth coalitions become centrally important when considered in a more international and multi-disciplinary context. The geographical differentiation and change overtime in what constitutes 'local and urban productivity' within and between countries are amplified and even modified when influenced by international forces. Changing of and responses to contested definitions of productivity seek to encompass and reflect geographical variation and uneven economic, social, political, cultural and environmental conditions and legacies in different places across the world. From one perspective, this involves an extension to broader spatial scales of the types of location marketing traditionally practiced by private developers. Alternatively, it may be seen as extending local governments' use of public goods provision to attract/retain desired residents and their integration into the economy. A more distinctive third dimension to the process involves specific investment in organizational assets to create a market in the territory's economic community (Bartelsman and Doms 2000).

The role of urban growth coalitions in urban economic development had tended to be ignored traditionally by economists who recognized only the significance of productivity at the national level (Dicken 2003). However, the new growth theory (Dukić 2012) is consistent with a sub-national regional perspective that views productivity as a major contributor to increasing the quality of life in terms of the quantity and nature of local jobs, and in the quantity of prices of goods and services produced locally. This conception of productivity gives a fluid and dynamic meaning to concepts of "urban economic development", emphasizing the importance of empirical analysis of the relations between endogenous factors and national transformative drivers. The underlying legacy forces in a region may hold some positions, discourses and practices in place beyond a time when they have any significant and immediate functional relationship to a region's economic development. The ongoing interaction between actors at the regional level and strategic maneuvers to mobilize regional resources exert a significant effect on the conceptionalizaiton of regional productivity. This conception provides a rich way to analyze the dynamics of interaction of context with innovative action (Baycan 2013). Because of these facts, the economics and particularly the urban studies literature on productivity has mainly focused on the effects at the local 
level; highlighting the positive role that regional endogenous factors may have on regional productivity through different channels. For example, urban and local $R \& D$ activities are required to be able to quickly and effectively adapt products to the needs and specificities of new markets (Pike and et al.,2006).

\section{5- Conclusion}

Under a traditional urban growth framework theory, achieving urban and local growth and productivity mainly a matter of investing in physical capital. Differences in stock and level of investment in infrastructure were regarded as the key elements of explaining output and regional economic returns. Hence, based on this thinking about how to spur economic development and growth and achieving productivity is rather straightforward: greater investment in infrastructure and stock enhancement would suffice to generate greater productivity and ultimately development. Further, if this approach is channeled to lagging urban regions, it would also contribute to economic convergence. But in new urban growth theory based on urban growth coalition, it is argued that achieving increased productivity and the introduction of a new dimension into urban policy modeling is much less straightforward than it may at first seem and that a clear distinction between the overall "physical capital- led productivity" and a more "multi-dimensional productivity and growth achieving process" conception based on social capital is needed in order to make urban growth policies more viable(following diagram).

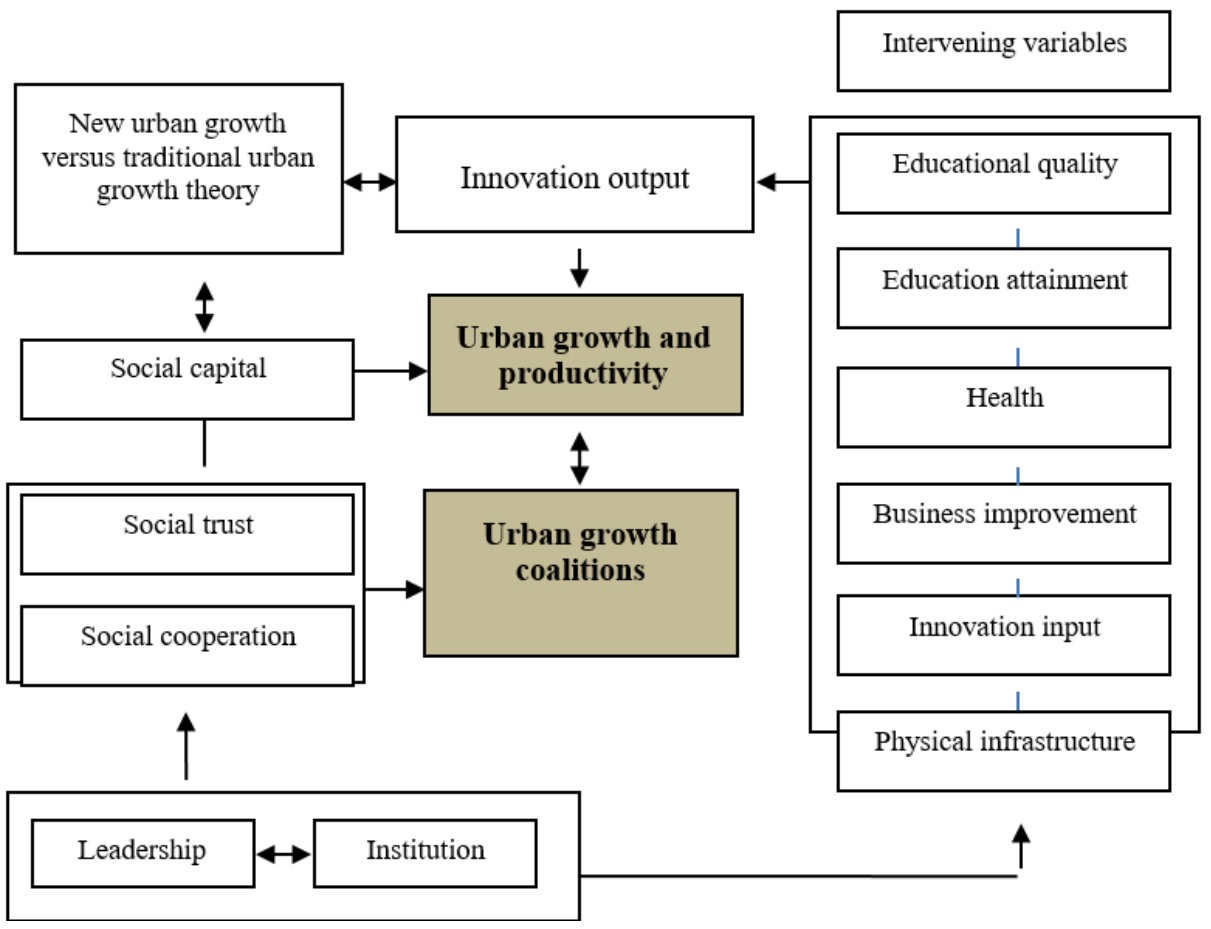

This paper offers a novel conceptual model, based on a mutual relationship between rurban growth coalitions and urban growth and productivity as a output at the local and urban level. In the light of the high policy importance of enhancement of urban economic development in lagging urban regions and the lack of a large sample empirical analysis, we argue that this paper provides a significant contribution to the extant literature and to the policy debate. Furthermore, in our conceptual model, we are able to examine how each urban region is or could be performing with greater productively through a change in inputs thus overcoming another major gap in the existing literature which has mainly focused on the output dimension in the productivity enhancement process. In view of the arguments put forward in this paper, it is possible to identify four urban growth policy areas that are related to the urban productivity model. 


\section{References}

[1] Adler, P. \& and Kwon, S. (2002). Social Capital: Prospects for a New Concept, The Academy of Management Review, Vol. 27, No. 1: 17-40.

[2] Ayios, A., Jeurissen, R., Manning, P., \& J. Spence, L. (2014). Social capital: a review from an ethics perspective. Business Ethics: A European Review, Volume 23 Number 1, 108-125.

[3] Bartelsman, E, Doms, M .2000. Understanding productivity: lessons from longitu-dinal microdata. Journal of Economic Literature 38:569-594.

[4] Bartelsman, E, Doms, M .2000. Understanding productivity: lessons from longitu-dinal microdata. Journal of Economic Literature 38:569-594.

[5] Baycan, T .2013. knowlege commercialization and valorization in regional economic development. Edward Elagar publishing, Usa, Massachusette.

[6] Castellani, D .2011. Foreign investments and productivity. Evidence from European regions. Quaderni del Dipartimento di Economia, Finanza e Statistica 83/2011. University of Perugia.

[7] Dukić, M .2012. Defining competitiveness through the theories of new economic geography and regional economy. J. Geogr. Inst. Cvijic 62: 49-64.

[8] Fukuchi, T .2000. Long-run development of a multi-regional economy. Papers in Regional Science 79:1-31

[9] Dukić, M .2012. Defining competitiveness through the theories of new economic geography and regional economy. J. Geogr. Inst. Cvijic 62: 49-64.

[10] Field, J. (2003). Social Capital. London: Routledge.

[11] Fukuyama, F. (2000). The Great Disruption. New York: Touchstone.

[12] Grootaert, C., \& van Bastelaer, T. (2002). The Role of Social Capital in Development: An Empirical Assessment. Cambridge: cambridge university press.

[13] Hamilton, G., \& Biggart, N. (1992). Market Culture and Authority:A Comparative Analysis of Management and Organization in the Far East. The Sociology of Economic Life, 181-224.

[14] Harding, A. (1991). The rise of urban growth coalitions, UK-style? Environment and Planning C: Government and Policy, 295-317.

[15] Holland, J. (2009). Young people and social capital: Uses and abuses? Youth Research, Vol 17(4): 331-350.

[16] Kovalainen, A. (2004). Rethinking the Revival of Social Capital and Trust in SocialTheory. Maidenhead and New York: Open University Press.

[17] Leonard, M. (2004). Bonding and Bridging Social Capital:Reflections from Belfast. Sociology, Volume 38(5): 927-944.

[18] Lin, N. (1999). Building a Network Theory of Social Capital, Journal of Connections, 22(1:28-51.

[19] Lin, N. (2001). Building a Network Theory of Social Capital. Aldine de Gruyter, 3-29.

[20] Mollenkopf, J. (2000). how to Study Urban Political Power, The City Reader, second edition, Richard T. legates and Fredric stout, Routledge.

[21] Molotch, H. (1976). The city as a growth machine. American Journal of Sociology, 82, 309-330.

[22] Pike, A, Rodriguez-Pose A, Tomaney J .2006. Local and Regional Development. Routledge press, London.

[23] Portes, A. (1995). The Economic Sociology of Immigration:Essays on Networks, Ethnicity and Entrepreneurship. New York: Russell Sage Foundation.

[24] Putnam, R. (1993). Making Democracy Work: Civic Traditions in Modern Italy. Princeton: Princeton University Press.

[25] Putnam, R. (2000). Bowling Alone: The Collapse and Revival of American Community. New York: Simon \& Schuster.

[26] Reimer, B., Lyons, T., Ferguson, N., \& Polanco, G. (2008). Social capital as social relations: the contribution of normative structures. The Sociological Review, 257-277.

[27] Staveren, I. \& Knorringa, P. (2006). Social Capital And Social Economics, Values in Public Life Seminars of Heythrop Institute for Religion, Ethics \& Public Life, London.

[28] Weber, M. (1978). The Protestant Ethic and the Spirit of Capitalism. London: George Allen \& Unwin. 